\title{
Perception of Community Pharmacists towards Dispensing Errors in Community Pharmacy Setting in Gondar Town, Northwest Ethiopia
}

\author{
Dessalegn Asmelashe Gelayee ${ }^{1}$ and Gashaw Binega Mekonnen ${ }^{2}$ \\ ${ }^{1}$ Department of Pharmacology, College of Medicine and Health Sciences, University of Gondar, Gondar, Ethiopia \\ ${ }^{2}$ Department of Clinical Pharmacy, College of Medicine and Health Sciences, University of Gondar, Gondar, Ethiopia \\ Correspondence should be addressed to Dessalegn Asmelashe Gelayee; desefikir4ever@gmail.com
}

Received 20 February 2017; Revised 31 March 2017; Accepted 9 April 2017; Published 22 May 2017

Academic Editor: Kumud K. Kafle

Copyright (C) 2017 Dessalegn Asmelashe Gelayee and Gashaw Binega Mekonnen. This is an open access article distributed under the Creative Commons Attribution License, which permits unrestricted use, distribution, and reproduction in any medium, provided the original work is properly cited.

\begin{abstract}
Background. Dispensing errors are inevitable occurrences in community pharmacies across the world. Objective. This study aimed to identify the community pharmacists' perception towards dispensing errors in the community pharmacies in Gondar town, Northwest Ethiopia. Methods. A cross-sectional study was conducted among 47 community pharmacists selected through convenience sampling. Data were analyzed using SPSS version 20. Descriptive statistics, Mann-Whitney $U$ test, and Pearson's Chisquare test of independence were conducted with $P \leq 0.05$ considered statistically significant. Result. The majority of respondents were in the 23-28-year age group $(N=26,55.3 \%)$ and with at least B.Pharm degree $(N=25,53.2 \%)$. Poor prescription handwriting and similar/confusing names were perceived to be the main contributing factors while all the strategies and types of dispensing errors were highly acknowledged by the respondents. Group differences $(P<0.05)$ in opinions were largely due to educational level and age. Conclusion. Dispensing errors were associated with prescribing quality and design of dispensary as well as dispensing procedures. Opinion differences relate to age and educational status of the respondents.
\end{abstract}

\section{Introduction}

One of the key functions of pharmaceutical care is dispensing medications, which involves selecting medications, transferring them to a container, and product labeling. Community pharmacies are often the first point of contact in the healthcare system because of easy accessibility and smooth approaches to patients [1]. These settings therefore have an important role in promoting rational drug use. According to the World Health Organization (WHO), rational use of drugs refers to situations when the right medicines are given to patients in appropriate doses and for an adequate period of time at the lowest cost to them and their community [2]. The International Pharmaceutical Federation (FIP) emphasizes that pharmacists are responsible for offering the required information for the quality use of medications [3]. However, comprehensive drug information has not been usually given to patients. Medicine's name, indications, dosage, and directions for use are more commonly communicated to patients compared to drug interactions, side effects, contraindications, precautions, and storage conditions [4]. Thus, proper training of drug dispensers to effectively communicate such aspects of drugs has been suggested [5].

Despite being cornerstones of therapy in healthcare, medications remained to be common sources of error and harms. Medication error (ME) refers to preventable events such as those related to prescribing, dispensing, and use which contribute to inappropriate use of medications and patient harm [6]. The most prevalent type of medication error is dispensing error and it refers to deviations from the prescription order regarding type, dose, storage, and so forth of drugs [7]. Such errors are a significant cause of preventable adverse events. The rates of dispensing errors were reported to be $0-45 \%$ across different studies [8]. In developing countries, 
the main types of dispensing errors include the supply of wrong drugs and wrong directions [9]. Several causes of dispensing errors have been reported including high workload, similar drug names, similar drug packaging, staffing levels, interruptions, and poor handwriting [9].

The dispensing errors are important targets for patient safety interventions [10]. However, there are few studies regarding medication errors in Ethiopia [11-13]. And to the best of our literature search, data regarding the perception of pharmacists towards dispensing errors are scarce. Therefore, this baseline study is intended to assess the perception of community pharmacists working in Gondar town, Northwest Ethiopia, towards the factors contributing to and perceived solution on dispensing errors in the community pharmacies.

\section{Methods}

A cross-sectional study was conducted among pharmacists working in the community pharmacies in Gondar town, Northwest Ethiopia, from October to December 2016. As of 2014, the town has one referral and teaching hospital, one private general hospital, a number of health centers and private clinics, and 53 medication retail outlets (19 pharmacies and 34 drug stores). In this study, community pharmacist refers to at least diploma holders in pharmacy education and community pharmacy refers to both drug stores and pharmacies.

The data collection instrument was a structured selfadministered questionnaire adopted from a previous study by Peterson et al. [14] with some modifications. It consisted of closed questions of yes/no type and 5-point Likert-type scale questions (never, rarely, sometimes, often, and very often) on sociodemographic characteristics, frequency of risks and actual dispensing errors, and perceived factors contributing to and strategies to minimize dispensing errors as well as common type of dispensing errors happening in community pharmacies.

The questionnaire was pretested on 5 pharmacy technicians working part-time in private pharmacies. Necessary modifications were made before distributing the questionnaires in person to the pharmacies. All consenting pharmacists $(N=47)$ working in the community pharmacies were involved in the study. The collected data were cleared and entered into the computer and analyzed by using the Statistical Package for Social Sciences (SPSS) version 20.0 for windows (SPSS Inc., Chicago, Illinois). Though the questionnaire was validated in the previous study, the modified one used in our study was also tested for its reliability. The reliability of the different subcomponents of the questionnaire was measured and Cronbach's alpha value was 0.821 (perceived factors contributing to dispensing errors, 11 items), 0.905 (perceived solutions to minimize dispensing errors, 10 items), and 0.856 (type of common dispensing errors, 4 items).

The results were described in terms of frequencies, percentages, and means \pm standard deviations. The relationships among variables were analyzed by using Mann-Whitney $U$ test and Pearson's Chi-square test of independence with a $P$ value $\leq 0.05$ considered statistically significant. An ethical clearance was taken from the school of Pharmacy, University
TABLE 1: Demographic characteristics and additional responses $(N=47)$.

\begin{tabular}{|c|c|}
\hline Variables & $N(\%)$ \\
\hline \multicolumn{2}{|l|}{ Sex } \\
\hline Female & $15(31.9)$ \\
\hline Male & $32(68.1)$ \\
\hline \multicolumn{2}{|c|}{ Age in year $($ mean $=30.6, S D=6.9)$} \\
\hline $23-28$ & $26(55.3)$ \\
\hline $29-51$ & $21(44.7)$ \\
\hline \multicolumn{2}{|l|}{ Educational level } \\
\hline Diploma & $22(46.8)$ \\
\hline BPharm & $24(51.1)$ \\
\hline MSc & $1(2.1)$ \\
\hline \multicolumn{2}{|c|}{$\begin{array}{l}\text { Work experience in community pharmacy (year) } \\
(\text { mean }=5.2, S D=3.6)\end{array}$} \\
\hline $1-4$ year & $25(53.2)$ \\
\hline $5-16$ year & $22(46.8)$ \\
\hline \multicolumn{2}{|c|}{ Additional work experience } \\
\hline Yes & $23(48.9)$ \\
\hline No & $24(51.1)$ \\
\hline \multicolumn{2}{|c|}{ Pharmacy ownership } \\
\hline Owner & $19(40.4)$ \\
\hline Employee & $28(59.6)$ \\
\hline \multicolumn{2}{|c|}{ Frequency of participating in dispensing within a week } \\
\hline$\leq 5$ days/week & $13(27.7)$ \\
\hline$\geq 6$ days/week & $34(72.3)$ \\
\hline \multicolumn{2}{|c|}{$\begin{array}{l}\text { Opinions on whether the risk of dispensing errors is } \\
\text { increasing. }\end{array}$} \\
\hline No & $26(55.3)$ \\
\hline Yes & $21(44.7)$ \\
\hline \multicolumn{2}{|c|}{$\begin{array}{l}\text { Opinions whether the actual errors in dispensing are } \\
\text { becoming more common }\end{array}$} \\
\hline No & $27(57.4)$ \\
\hline Yes & $20(42.6)$ \\
\hline
\end{tabular}

of Gondar, and all respondents were asked for their consent before participation in the study.

\section{Result}

Forty-seven pharmacists working in the community pharmacies located in Gondar town completed and returned the questionnaires making a $100 \%$ response rate. The majority were male $(N=32,68.1 \%)$, in the 23-28-year age group $(N=26,55.3 \%)$, at least B. Pharm degree holders $(N=25$, $53.2 \%)$, with work experience of 4 years and below $(N=25$, $53.2 \%)$, and employee $(N=28,59.6 \%)$. Thirty-four $(72.3 \%)$ respondents work 6 days and above per week. An increase in frequency of risks and actual dispensing errors was opined by $21(44.7 \%)$ and $20(42.6 \%)$ respondents, respectively (Table 1).

Perceived factors that contribute to dispensing errors in community pharmacies were assessed using five-point Likert-type questions as shown in Table 2. When the factors 
TABLE 2: Perceived factors contributing to the dispensing errors $(N=47)$.

\begin{tabular}{|c|c|c|c|c|c|}
\hline \multirow{2}{*}{ Variables } & \multicolumn{5}{|c|}{ Responses $N(\%)$} \\
\hline & Never & Rarely & Sometimes & Often & Very often \\
\hline Poor prescription hand writing & 0 & $2(4.2)$ & $10(21.3)$ & $13(27.7)$ & $22(46.8)$ \\
\hline Similar/confusing names & $1(2.1)$ & $11(23.5)$ & $18(38.3)$ & $16(34.0)$ & $1(2.1)$ \\
\hline Work load & $3(6.4)$ & $16(34.0)$ & $12(25.5)$ & $9(19.2)$ & $7(14.9)$ \\
\hline Lack of time to talk with patients & $9(19.2)$ & $12(25.5)$ & $17(36.2)$ & $5(10.6)$ & $4(8.5)$ \\
\hline Packaging \& labeling & 7 (14.9) & $15(31.9)$ & $19(40.4)$ & $4(8.5)$ & $2(4.3)$ \\
\hline Interruption & $5(10.6)$ & $17(36.2)$ & $17(36.2)$ & $3(6.4)$ & $5(10.6)$ \\
\hline Design of dispensary & $10(21.3)$ & $12(25.5)$ & $12(25.5)$ & $7(14.9)$ & $6(12.8)$ \\
\hline Pharmacist fatigue of any cause & $3(6.4)$ & $21(44.7)$ & $14(29.8)$ & $7(14.9)$ & $2(4.2)$ \\
\hline Noise & $10(21.3)$ & $14(29.8)$ & $12(25.5)$ & $5(10.6)$ & $6(12.8)$ \\
\hline Lack of privacy & $14(29.8)$ & $10(21.3)$ & $9(19.1)$ & $4(8.5)$ & $10(21.3)$ \\
\hline Job dissatisfaction & $14(29.8)$ & $16(34.0)$ & $8(17.0)$ & $4(8.5)$ & $5(10.7)$ \\
\hline
\end{tabular}

Note. The above responses were arranged in descending order for the sum of responses (sometimes/often/very often).

TABLE 3: Perceived strategies that may reduce the risk of dispensing errors $(N=47)$.

\begin{tabular}{|c|c|c|c|c|c|}
\hline \multirow{2}{*}{ Variables } & \multicolumn{5}{|c|}{ Responses $N(\%)$} \\
\hline & Never & Rarely & Sometimes & Often & Very often \\
\hline Improving prescription hand writing & 0 & $2(4.2)$ & $8(17.0)$ & $7(14.9)$ & $30(63.9)$ \\
\hline Checking original prescription & 0 & $2(4.2)$ & $6(12.8)$ & $13(27.7)$ & $26(55.3)$ \\
\hline Having mechanism for checking dispensing procedures & 0 & $2(4.2)$ & $7(14.9)$ & $17(36.2)$ & $21(44.7)$ \\
\hline Counseling patients at the time of supply & $1(2.1)$ & $1(2.1)$ & $3(6.4)$ & $10(21.3)$ & $32(68.1)$ \\
\hline Keeping drug knowledge up-to-date & $1(2.1)$ & $2(4.2)$ & $6(12.8)$ & $7(14.9)$ & $31(66.0)$ \\
\hline Systematic dispensing workflow & 0 & $3(6.4)$ & $13(27.7)$ & $15(31.9)$ & $16(34.0)$ \\
\hline Privacy when counseling patients & $1(2.1)$ & $3(6.4)$ & $4(8.5)$ & $10(21.3)$ & $29(61.7)$ \\
\hline Having drug names that are distinctive & $1(2.1)$ & $4(8.5)$ & $10(21.3)$ & $18(38.3)$ & $14(29.8)$ \\
\hline Reducing workloads on pharmacist & $1(2.1)$ & $5(10.7)$ & $10(21.3)$ & $15(31.9)$ & $16(34.0)$ \\
\hline Improving packaging \& labeling & $2(4.2)$ & $4(8.5)$ & $10(21.3)$ & $17(36.2)$ & $14(29.8)$ \\
\hline
\end{tabular}

Note. The above responses were arranged in descending order for the sum of responses (sometimes/often/very often).

are placed in descending order as usual causes of dispensing errors (sometimes/often/very often), poor prescription handwriting $(N=45,95.8 \%)$ and similar/confusing names $(N=35,74.4 \%)$ are on the top while job dissatisfaction $(N=17,36.2 \%)$ is on the bottom.

Similarly, all the listed strategies were taken as very effective measures (sometimes/often/very often) to reduce dispensing errors by $41(87.2 \%)$ to $45(95.7 \%)$ respondents (Table 3).

Perceived dispensing errors commonly happening in community pharmacies (sometimes/often/very often) were dispensing contraindicated drugs $(N=29,61.8 \%)$, dispensing with wrong dosing instruction $(N=24,51.1 \%)$, dispensing wrong type of drug $(N=21,44.7 \%)$, and dispensing wrong dosage form $(N=19,40.4 \%)$ (Table 4$)$.

Pearson's Chi-square test of independence demonstrated the presence of association between sex (male/female) of respondents and the opinion that there is an increase in frequency of actual dispensing errors in community pharmacies. Thus, males were more likely to suggest that there is an increase in actual dispensing errors compared to females (17 (53.1\%) versus 3 (20\%); $P=0.032$; Table 5).
Mann-Whitney $U$ test was carried out to test group differences (based on demographic factors) on the perceived factors contributing to dispensing errors and strategies to minimize dispensing errors as well as common dispensing errors happening at the level of community pharmacies in Gondar town, Northwest Ethiopia. There were differences regarding some of the factors as causes for dispensing errors based on age (one factor), educational status (four factors), and work experience (one factor). Age $(P=0.032)$, educational level $(P=0.006)$, and work experience $(P=0.015)$ affected respondents' opinion on poor prescription handwriting as a cause for dispensing errors. Based on educational level, there were differences in considering interruption $(P=$ $0.023)$, design of dispensary $(P=0.039)$, and lack of privacy $(P=0.043)$ as factors contributing to dispensing errors (Table 6).

Similarly, Mann-Whitney $U$ test on perceived strategies that can minimize dispensing errors revealed age, sex, work experience, and dispensing frequency based differences. Group differences were noted in relation to improving prescription handwriting based on sex $(P=0.007)$, age $(P=$ $\left.0.009^{*}\right)$, and work experience $(P=0.030)$. In addition, the 
TABLE 4: Perceived type of dispensing errors in community pharmacies $(N=47)$.

\begin{tabular}{|c|c|c|c|c|c|}
\hline \multirow{2}{*}{ Variables } & \multicolumn{5}{|c|}{ Responses $N(\%)$} \\
\hline & Never & Rarely & Sometimes & Often & Very often \\
\hline Dispensing contraindicated drug & $9(19.1)$ & $9(19.1)$ & $20(42.7)$ & $9(19.1)$ & 0 \\
\hline Dispensing with wrong dosing instruction & $5(10.6)$ & $18(38.3)$ & $14(29.9)$ & $9(19.1)$ & $1(2.1)$ \\
\hline Dispensing wrong type of drug & $11(23.4)$ & $15(31.9)$ & $14(29.8)$ & $5(10.6)$ & $2(4.3)$ \\
\hline Dispensing wrong dosage form & $11(23.4)$ & $17(36.2)$ & $12(25.5)$ & $5(10.6)$ & $2(4.3)$ \\
\hline
\end{tabular}

Note. The above responses were arranged in descending order for the sum of responses (sometimes/often/very often).

TABLE 5: Relationship between demographic factors and opinion if frequency of risk and actual dispensing errors are increasing $(N=47)$.

\begin{tabular}{|c|c|c|c|c|}
\hline \multirow{3}{*}{ Variables } & \multicolumn{4}{|c|}{ Responses N (\%) } \\
\hline & \multirow{2}{*}{\multicolumn{2}{|c|}{$\begin{array}{l}\text { Risk of dispensing errors is increasing } \\
\qquad(N=21) \\
N(\%)\end{array}$}} & \multicolumn{2}{|c|}{$\begin{array}{l}\text { Actual dispensing errors are increasing } \\
\qquad(N=20)\end{array}$} \\
\hline & & & $N(\%)$ & \\
\hline \multicolumn{5}{|l|}{ Sex } \\
\hline Female $(N=15)$ & $4(26.7 \%)$ & $X^{2}=2.892, \mathrm{df}=1$ & $3(20 \%)$ & $X^{2}=4.584, \mathrm{df}=1$ \\
\hline Male $(N=32)$ & $17(53.1 \%)$ & $P=0.089$ & $17(53.1 \%)$ & $P=0.032^{*}$ \\
\hline \multicolumn{5}{|l|}{ Age (years) } \\
\hline $23-28(N=26)$ & $9(34.6 \%)$ & $X^{2}=2.385, \mathrm{df}=1$ & $10(38.5 \%)$ & $X^{2}=0.399, \mathrm{df}=1$ \\
\hline $29-51(N=21)$ & $12(57.1 \%)$ & $P=0.122$ & $10(47.6 \%)$ & $P=0.528$ \\
\hline \multicolumn{5}{|l|}{ Educational level } \\
\hline Diploma $(N=22)$ & $8(36.4 \%)$ & $X^{2}=1.158, \mathrm{df}=1$ & $9(40.9 \%)$ & $X^{2}=0.046, \mathrm{df}=1$, \\
\hline $\begin{array}{l}\text { BPharm degree and above } \\
(N=25)\end{array}$ & $13(52 \%)$ & $P=0.282$ & $11(44 \%)$ & $P=0.831$ \\
\hline \multicolumn{5}{|l|}{ Work experience (years) } \\
\hline $1-4$ year $(N=25)$ & $10(40 \%)$ & $X^{2}=0.473, \mathrm{df}=1$ & $11(44 \%)$ & $X^{2}=0.046, \mathrm{df}=1$ \\
\hline $5-16$ year $(N=22)$ & $11(50 \%)$ & $P=0.491$ & $9(40.9 \%)$ & $P=0.831$ \\
\hline \multicolumn{5}{|l|}{ Additional work experience } \\
\hline $\mathrm{No}(N=24)$ & $11(45.8 \%)$ & $X^{2}=0.026, \mathrm{df}=1$ & $9(37.5 \%)$ & $X^{2}=0.512, \mathrm{df}=1$ \\
\hline Yes $(N=23)$ & $10(43.5 \%)$ & $P=0.871$ & $11(47.8 \%)$ & $P=0.474$ \\
\hline \multicolumn{5}{|l|}{ Pharmacy ownership } \\
\hline Owner $(N=19)$ & $8(42.1 \%)$ & $X^{2}=0.086, \mathrm{df}=1$ & $6(31.6 \%)$ & $X^{2}=1.571, \mathrm{df}=1, P$ \\
\hline Employee $(N=28)$ & $13(46.4 \%)$ & $P=0.770$ & $14(50 \%)$ & $=0.210$ \\
\hline \multicolumn{5}{|l|}{ Dispensing practice } \\
\hline$\leq 5$ days/week $(N=13)$ & $4(30.8 \%)$ & $X^{2}=1.407, \mathrm{df}=1$ & $5(38.5 \%)$ & $X^{2}=1.230, \mathrm{df}=1$ \\
\hline$\geq 6$ days/week $(N=34)$ & $17(50 \%)$ & $P=0.236$ & $15(44.1 \%)$ & $P=0.726$ \\
\hline
\end{tabular}

Note. ${ }^{*}=$ significant $(P \leq 0.05), \mathrm{df}=$ degrees of freedom, $X^{2}=$ Pearson's Chi-square value.

following differences were also found: reducing workloads on pharmacist versus age $(P=0.096)$; keeping drug knowledge up-to-date versus sex $(P=0.003)$ and additional work experience $(P=0.034)$; having drug names that are distinctive versus dispensing frequency $(P=0.028)$; systematic dispensing workflow versus age $(P=0.044)$; having mechanism for checking dispensing procedures versus age $(P=0.049)$ (Table 7).

In relation to perceived type of common dispensing errors, group differences were observed only on dispensing with wrong dosing instruction. Thus, there were age $(P=$ $0.027)$, work experience $(P=0.004)$, and pharmacy ownership $(P=0.008)$ based opinion differences (Table 8$)$.

\section{Discussion}

Dispensing medication is inherently risky and dispensing errors are inevitable occurrences in community pharmacies across the world [9]. This is the first study to evaluate the attitude towards dispensing error of pharmacists working in the private setting in Ethiopia. The settings were chosen because they are the most easily accessible facilities to the community and there is high patient flow and dispensing practice. Nearly half of the respondents agreed that the frequency of risks as well as actual dispensing errors is increasing and there is no significant difference $(P>0.05)$ among participants on these views except for sex $(P=0.032)$. Male pharmacists were more likely to suggest that there is an increase in actual dispensing errors compared to females. Despite this, the finding signals the need for further prospective studies on estimating actual dispensing errors and implementing strategies to minimize dispensing errors. In our study, $20(42.6 \%)$ respondents opined that actual dispensing errors are increasing and this is somehow lower compared to $55.5 \%$ and $47 \%$ respondents in previous studies conducted in Saudi Arabia and Australia [14, 15]. 


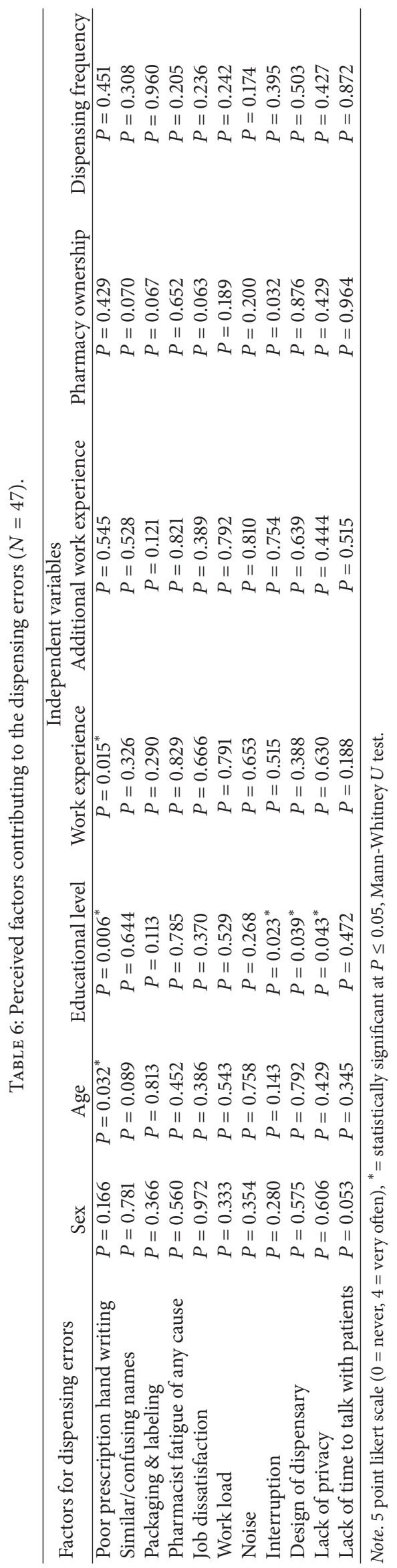




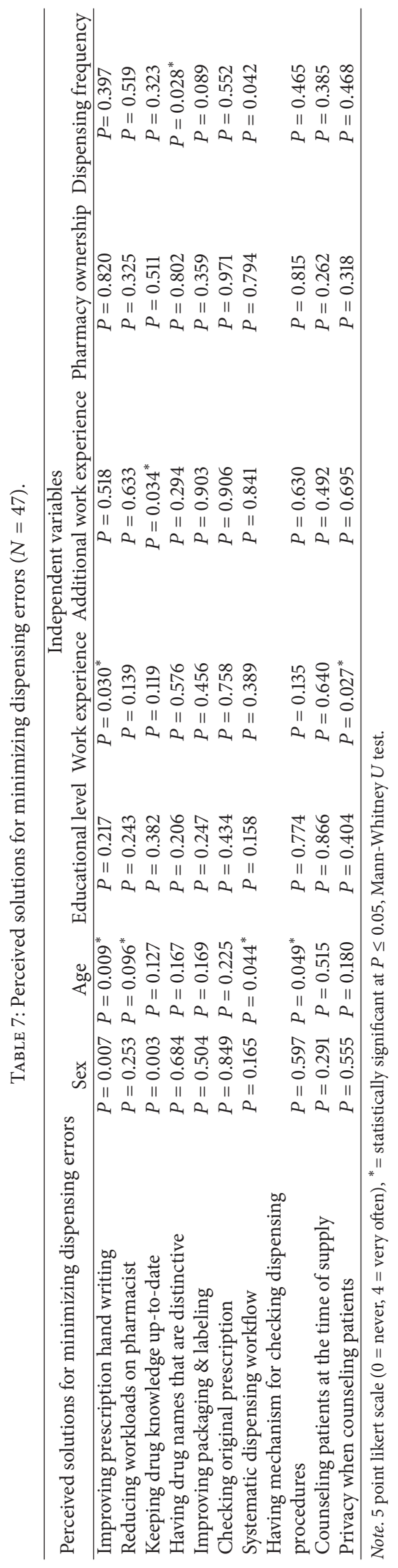




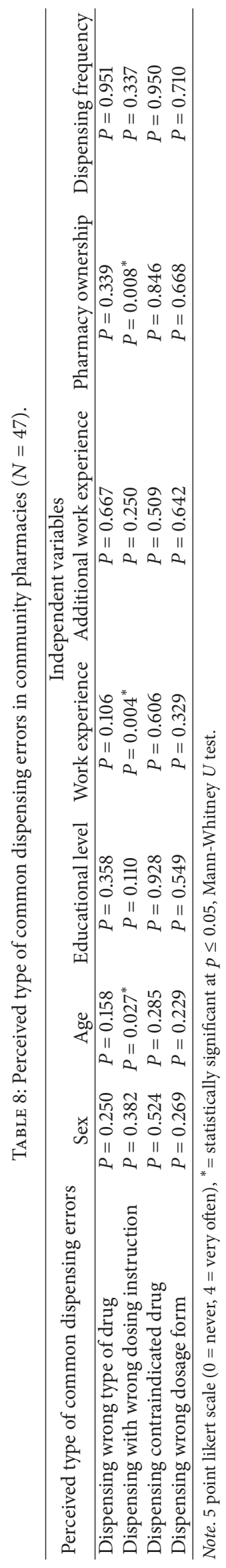


All the listed factors were well recognized by the respondents as a potential cause for dispensing errors. Poor prescription writing is cited as the most frequent cause of dispensing errors followed by confusing drug names. Both factors were reported in previous studies as major causes of dispensing errors $[15,16]$. Respondents who are in the age group of 29-51 years, degree holders, and with more experience rated highly $(P<0.05)$ poor prescription handwriting when compared to their counter groups. It seems that the ability to detect dispensing error increases with age, educational status, and work experience of pharmacists. Despite the fact that there is a need to improve job satisfaction among pharmacists working in Ethiopia [17], it is the factor least appreciated by the respondents as a cause for dispensing errors. Most of the other factors were acknowledged relatively similarly and no significant group differences were found. The exceptions were on the effects of interruption, design of dispensary, and lack of privacy. Respondents with higher educational status rate interruption, design of dispensary, and lack of privacy as factors contributing to dispensing errors highly $(P<0.05)$ than diploma holders. It seems that, in private pharmacy establishments where there is high patient flow and absence of pharmacy assistants, the above factors are meaningful causes of dispensing errors. A similar finding is reported by Al-Arifi [15].

All the strategies listed in the present study were strongly appreciated by the respondents for reducing dispensing errors and this is consistent with previous studies [14, 15]. Labeling and storage of containers in the dispensary, interruptions, and distractions were also identified as main causes of dispensing errors in a hospital setting [18]. However, group differences based on age, sex, work experience, and dispensing frequency were found. Most of the differences in opinions were based on age and thus the older age group were more likely to rate the strategies highly $(P<0.05)$ than their counter groups. Since in our study age is associated with work experience $(P<0.05)$, thus the older group seems to have more experience to appreciate the strategies highly than their counter groups.

Several types of dispensing errors were acknowledged by the respondents but dispensing contraindicated drugs and dispensing with wrong dosing instructions were found to be on top of the others. It seems that even with the routine dispensing practice characterized by provision of dosing instruction [4], there exists gap making interventions mandatory. The older aged group, more experienced ones, and the owners rated dispensing with wrong dosing instruction significantly higher $(P<0.05)$ than their counter groups.

This study however has limitation of small sample size. This is because the number of pharmacists engaged in community pharmacy setting is low in the town. Thus, it may not be generalized to community pharmacists in the nation.

The findings of this study imply that community pharmacists believe that the risks and actual dispensing errors are increasing in the area. Perceived factors causing dispensing errors were related to prescribing quality and design of dispensary as well as dispensing procedures. Thus, training to minimize dispensing errors is very much needed and should also consider the identified factors.

\section{Conclusion}

The risks and actual dispensing errors are increasing in community pharmacies according to the respondents and several contributing factors and strategies against dispensing errors were identified. Most of the time when there are group differences, it is either because of educational level or age of the participants. We suggest further prospective studies in estimating the actual dispensing errors and interventions shall be inclusive of the strategies identified in the present study.

\section{Additional Points}

Availability of Data and Material. The main document from which this manuscript was developed is deposited in the Pharmacy School of University of Gondar.

\section{Ethical Approval}

Ethical clearance was taken from Research Ethics Review Committee of Department of Pharmacology, University of Gondar.

\section{Consent}

An informed consent was obtained from the participants.

\section{Conflicts of Interest}

The authors declare that there are no conflicts of interest regarding the publication of this paper.

\section{Authors' Contributions}

Dessalegn Asmelashe Gelayee drafted the proposal. Dessalegn Asmelashe Gelayee and Gashaw Binega Mekonnen contributed to data collection as well as the statistical analysis. Dessalegn Asmelashe Gelayee developed the manuscript and both Gashaw Binega Mekonnen and Dessalegn Asmelashe Gelayee read and approved the final manuscript.

\section{Acknowledgments}

The authors appreciate the involvement of their colleagues as well as the respondents of the study in data collection.

\section{References}

[1] R. Adepu and B. Nagavi, "General practitioners' perceptions about the extended roles of the community pharmacists in the state of Karnataka: a study," Indian Journal of Pharmaceutical Sciences, vol. 68, no. 1, pp. 36-40, 2006.

[2] WHO., The Rational Use of Drugs. Report of a Conference of Experts, Nairobi, 25-29 November 1985, World Health Organization, Geneva, 1987.

[3] International Pharmaceutical Federation, "Standards for quality of pharmacy services".

[4] F. Ax, J.-O. Brånstad, and T. Westerlund, "Pharmacy counselling models: a means to improve drug use," Journal of Clinical Pharmacy and Therapeutics, vol. 35, no. 4, pp. 439-451, 2010. 
[5] P. Mishra, E. H. Hansen, S. Sabroe, and K. K. Kafle, "Adherence is associated with the quality of professional-patient interaction in Directly Observed Treatment Short-course, DOTS," Patient Education and Counseling, vol. 63, no. 1-2, pp. 29-37, 2006.

[6] US Food and Drug Administration, "Medication Errors, US Department of Health and Human Services," http://www.fda .gov/Drugs/DrugSafety/MedicationErrors/default.htm.

[7] S. Szeinbach, E. Seoane-Vazquez, A. Parekh, and M. Herderick, "Dispensing errors in community pharmacy: perceived influence of sociotechnical factors," International Journal for Quality in Health Care, vol. 19, no. 4, pp. 203-209, 2007.

[8] K.-C. Cheung, M. L. Bouvy, and P. A. G. M. De Smet, "Medication errors: the importance of safe dispensing," British Journal of Clinical Pharmacology, vol. 67, no. 6, pp. 676-680, 2009.

[9] K. L. James, D. Barlow, R. McArtney, S. Hiom, D. Roberts, and C. Whittlesea, "Incidence, type and causes of dispensing errors: a review of the literature," International Journal of Pharmacy Practice, vol. 17, no. 1, pp. 9-30, 2009.

[10] H. P. Puspitasari, P. Aslani, and I. Krass, "How do Australian metropolitan and rural pharmacists counsel consumers with prescriptions?" Pharmacy World and Science, vol. 31, no. 3, pp. 394-405, 2009.

[11] O. Sada, A. Melkie, and W. Shibeshi, "Medication prescribing errors in the medical intensive care unit of Tikur Anbessa Specialized Hospital, Addis Ababa, Ethiopia," BMC Research Notes, vol. 8, no. 1, article 448, 2015.

[12] S. A. Feleke, M. A. Mulatu, and Y. S. Yesmaw, "Medication administration error: magnitude and associated factors among nurses in Ethiopia," BMC Nursing, vol. 14, no. 1, article no. 53, 2015.

[13] M. G. Dedefo, A. H. Mitike, and M. T. Angamo, "Incidence and determinants of medication errors and adverse drug events among hospitalized children in West Ethiopia," BMC Pediatrics, vol. 16, no. 1, article 81, 2016.

[14] G. M. Peterson, M. S. H. Wu, and J. K. Bergin, "Pharmacists' attitudes towards dispensing errors: their causes and prevention," Journal of Clinical Pharmacy and Therapeutics, vol. 24, no. 1, pp. 57-71, 1999.

[15] M. N. Al-Arifi, "Community pharmacists' attitudes toward dispensing errors at community pharmacy setting in Central Saudi Arabia," Saudi Pharmaceutical Journal, vol. 22, no. 3, pp. 195-202, 2014.

[16] P. Knudsen, H. Herborg, A. R. Mortensen, M. Knudsen, and A. Hellebek, "Preventing medication errors in community pharmacy: root-cause analysis of transcription errors," Quality and Safety in Health Care, vol. 16, no. 4, pp. 285-290, 2007.

[17] G. B. Gebretekle and T. G. Fenta, "Assessment of the pharmacist's workforce in Ethiopia," Ethiopian Journal of Health Development, vol. 27, no. 2, pp. 124-133, 2013.

[18] A. Beso, B. D. Franklin, and N. Barber, "The frequency and potential causes of dispensing errors in a hospital pharmacy," Pharmacy World and Science, vol. 27, no. 3, pp. 182-190, 2005. 


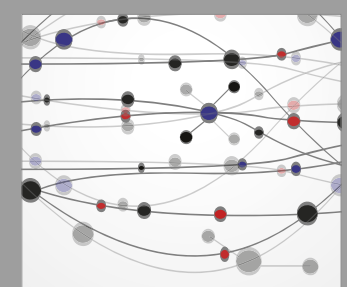

The Scientific World Journal
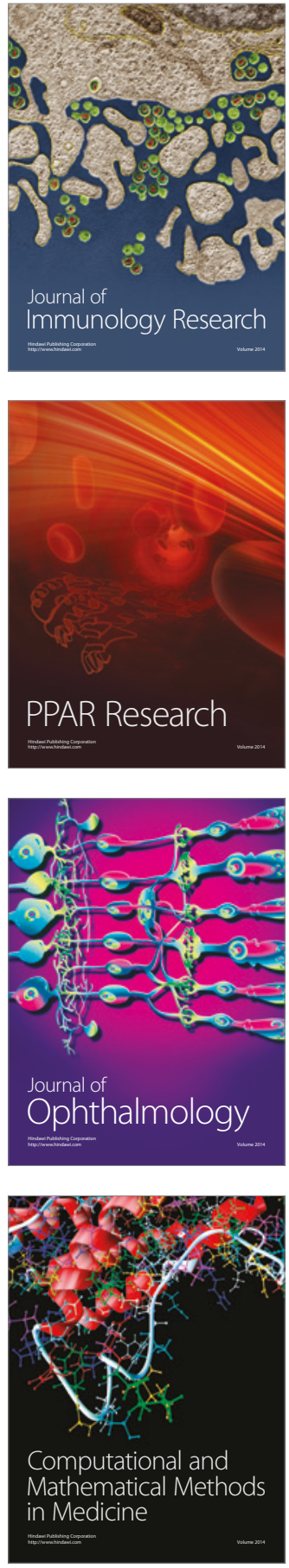

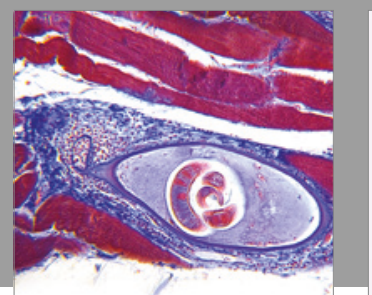

Gastroenterology Research and Practice
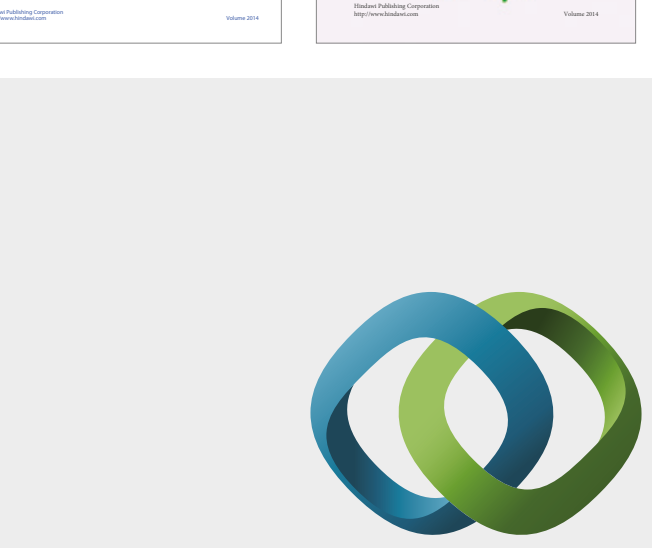

\section{Hindawi}

Submit your manuscripts at

https://www.hindawi.com
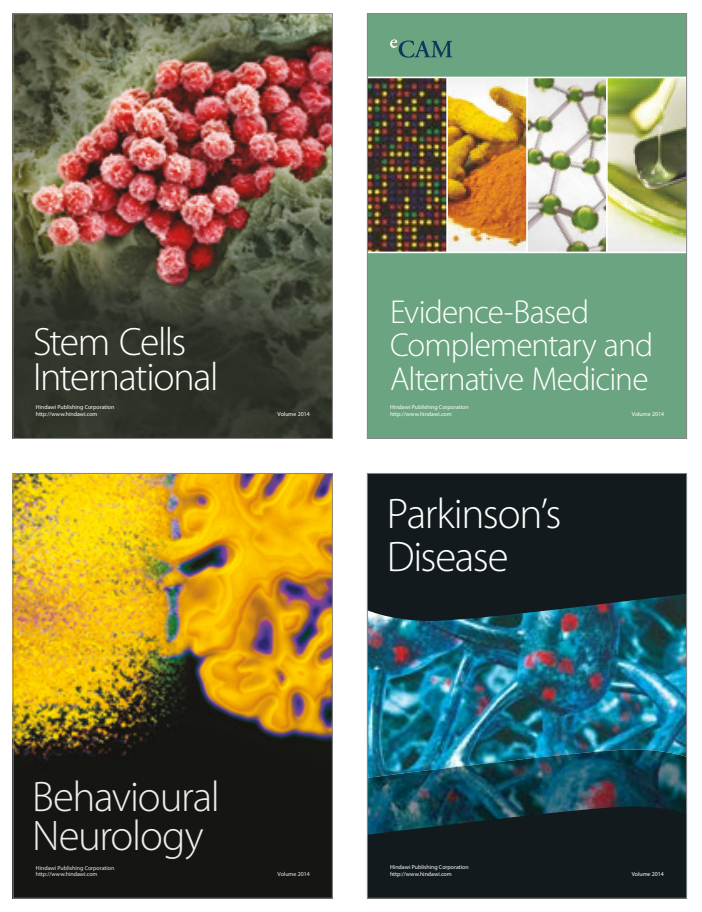
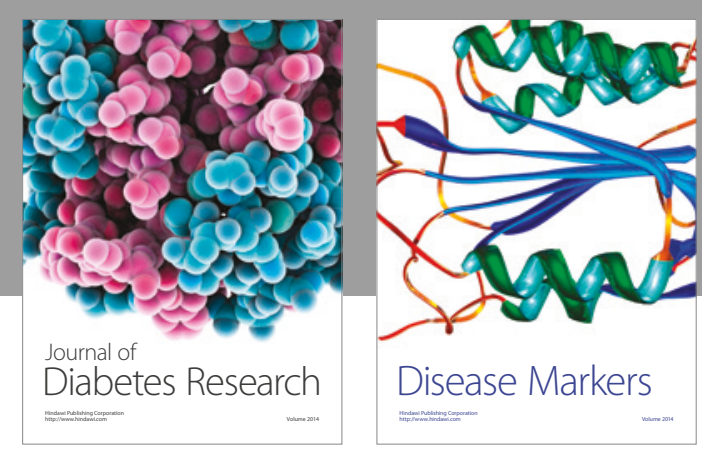

Disease Markers
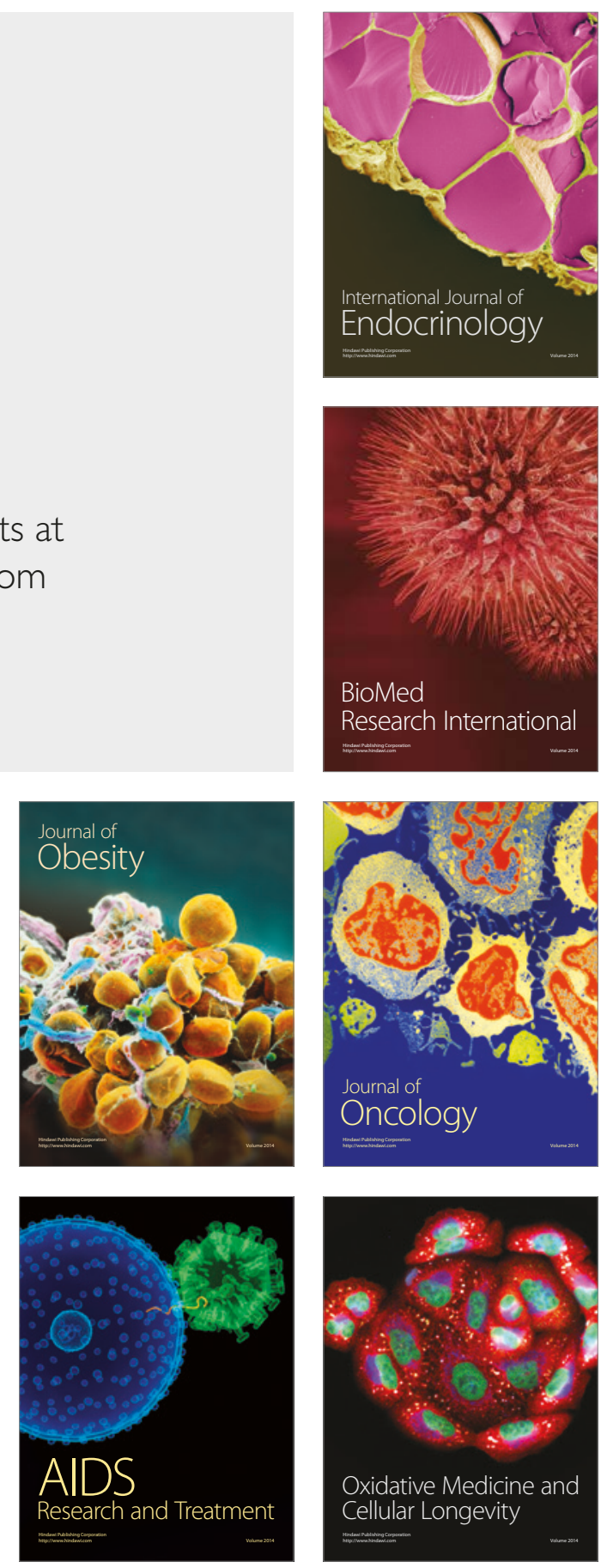